\title{
Lessons from the outbreak of food poisoning at Stanley Royd Hospital: what are health authorities doing now?
}

\author{
MUKESH KAPILA, ROGER BUTTERY
}

\begin{abstract}
The committee of inquiry into the outbreak of food poisoning at Stanley Royd Hospital identified serious deficiencies in the management of the outbreak and urged all health authorities to learn from the incident and prepare adequate plans for dealing with any future outbreaks. A survey of district health authorities in England showed that most authorities do not yet have a written plan or that their plans are incomplete and inadequate.

The appreciable resistance to such planning suggests that most health authorities would be unable to deal with outbreaks of food poisoning effectively and efficiently.
\end{abstract}

\section{Introduction}

The committee of inquiry into the outbreak of food poisoning at Stanley Royd Hospital identified several shortcomings in the management of the outbreak. ${ }^{1}$ These included the absence of a defined plan to deal with such a major incident, unsatisfactory communication, and confusion over individual responsibilities. In its report the committee urged health authorities to examine their current strategies for managing a major outbreak of food poisoning or communicable disease; this prompted us to perform a national survey of such action being taken.

\section{Methods}

We sent a letter to the general managers of all 192 district health authorities in England asking if they had contingency plans for dealing with a major outbreak of food poisoning or communicable disease in hospitals or the community. A copy of any existing plan was also requested. The responses received were analysed according to whether health authorities claimed that they had a plan or not.

The essential features recommended by the committee of inquiry and the consequent "model Wakefield plan" (Wakefield Health Authority Control of Infection Committee, unpublished report) are outlined below.

Objectives-What does the plan cover? What does it exclude? Is there a clear statement of its objectives?

Responsibilities-Is there a specific outbreak control team? Do its members have defined responsibilities to manage clearly identified tasks?

Communication-Is there satisfactory provision for maintaining clear communication within the authority-for instance, different departments, management, and staff-and with other agencies-for instance, local authority, Public Health Laboratory Service, regional health authority, Communicable Disease Surveillance Centre, Department of Health and Social Security, etc? Who is going to tell what and when to patients, relatives, and the media?

Process-Is the procedure for setting the plan in action explicit? Is there a set procedure for meetings of the control team, a check list of items to discuss, and a clear method of sharing information within the team? Is there adequate support from management and other agencies?

Review-Is there a regular timetable to review and keep the plan up to date? Is it recognised that the plan would be revised after experience of an actual outbreak in the district?

Department of Community Medicine, Cambridge Health Authority, Cambridge CB2 2PF

MUKESH KAPILA, MSC, MRCGP, senior registrar in community medicine ROGER BUTTERY, MFCM, specialist in community medicine and medical officer of environmental health

Correspondence to: Dr Buttery.
Each of these features was qualitatively assessed by one observer in the plans received and scored as $(a)$ absent; $(b)$ present but unclear or incomplete; or $(c)$ present and reasonably explicit. In addition, the overall ${ }^{5}$ quality of the plan was assessed as $(a)$ irrelevant; $(b)$ having major deficiencies; or $(c)$ reasonably adequate.

\section{Results}

Of the 192 health authorities contacted, 134 replied within six weeks. giving a response of $70 \%$. One hundred and thirty one responses $(68 \%)$ were $\overrightarrow{-}$ complete enough to be used for further analysis. Of these, $48(37 \%)$ had ${ }^{\omega}$ plans and $83(63 \%)$ did not. Of those that did not have plans only 40 o authorities said that plans were being prepared.

Twenty nine plans were received and these were examined for the recommended essential features outlined above; the table summarises the $w$ results. Only three of 29 plans were considered to be reasonably adequate. O5 Most-24 (83\%) - had major deficiencies, and two $(7 \%)$ were irrelevant to outbreak control, being no more than descriptive notes of a few selected communicable diseases. Further analysis (table) showed that over a third of $\mathrm{N}$ all plans had no defined objectives, responsibilities, or procedures for $\vec{\circ}$ communication. When these features were present they were generally $\supset$ vague. Most plans did not have any explicit provision for regular review or $N$ revision after experience of an actual outbreak. Some of the plans submitted were nearly 10 years old.

No $(\%)$ of plans with the essential features of an adequate plan to control outbreaks $n=29)$

\begin{tabular}{lccc}
\hline Feature & Absent & $\begin{array}{c}\text { Present but } \\
\text { unclear }\end{array}$ & $\begin{array}{c}\text { Present and } \\
\text { quite clear }\end{array}$ \\
\hline Objectives & $12(41)$ & $13(45)$ & $4(14)$ \\
Responsibilities & $11(38)$ & $9(3)$ & $9(31)$ \\
Communication & $10(34)$ & $13(45)$ & $6(21)$ \\
Process & $6(21)$ & $17(58)$ & $6(21)$ \\
Review & $25(86)$ & $2(7)$ & $2(7)$ \\
\hline
\end{tabular}

\section{Discussion}

We found that most district health authorities in England do not have a written plan for the management of an outbreak of food $\delta$ poisoning or communicable disease. The plans that were examined 3 were generally seriously deficient in essential components.

While at least 40 districts gave assurances that they are planning shortly to adopt written procedures for the control of outbreaks, the $\sigma$ intentions of at least 43 (and up to 101 ) other districts were not clear. Evidence suggests that most (up to half of all English health districts) are not preparing written plans for dealing with outbreaks $N$ of food poisoning or communicable disease. Many more are relying $\underset{\omega}{\omega}$ on plans that in our opinion are incomplete or inadequate. This implies that the lessons of the outbreak at Stanley Royd Hospital o have not yet been learnt. ${ }^{1}$ To our knowledge, no guidance has yet $\mathbb{\complement}$ been issued by the Department of Health and Social Security.

Some respondents gave reasons for their health authorities not $T$ producing a formal outbreak control plan. One such reason was satisfaction with current procedures. Such comments as "we deal $\stackrel{\Phi}{\Phi}$ with events as they occur"; "the personal links between me and my $\stackrel{\mathbb{\Omega}}{\square}$ staff have been adequate to date"; and "the plan is in my head" typify the smug attitude of some senior members of staff-an attitude that was severely criticised by the committee of inquiry. ${ }^{1}$ The comments also reveal an inconsiderate attitude to junior staff, who may have to deal with an emergency when the principal officer 
is absent. Another reason given was the technical difficulty of formulating a plan: "the wide ranging nature of our health district prevents any formal written detailed plan"; "a single contingency plan is unhelpful"; "I have personal and professional reservations as to the value of such plans"; "I do not know what you define as a plan"; "we are awaiting further guidance from DHSS"; "we cannot get members of our control of infection committee to agree."

In 1983 laboratories reported 15168 cases of salmonella and other bacterial food poisoning in England and Wales. ${ }^{2}$ This represents a $20 \%$ increase since 1982 and nearly a doubling of the cases reported in 1970. Most of this upward trend is probably real and not just the result of better detection, investigation, and reporting. ${ }^{3}$ Many of these outbreaks occur in hospitals: of the 191 outbreaks reported in institutions in 1983, $37(19 \%)$ occurred in hospitals. ${ }^{2}$ Hospitals also account for about one third of all reported outbreaks of salmonella poisoning occurring outside the home. ${ }^{4}$ This is important to public health for several reasons-namely, patients, especially the elderly and infants, may suffer considerable morbidity; services may be seriously disrupted; and hospitals may become the focus of infection with strains possessing multiple antibiotic resistance. ${ }^{5}$

Problems in the organisation of the investigation and management of suspected food poisoning in hospitals have been highlighted previously (Communicable Disease Surveillance Centre, unpublished report) and recently.' We therefore reiterate that all health authorities should prepare adequate and up to date plans to ensure that they are capable of dealing with outbreaks of food poisoning effectively and efficiently.

A model outbreak control plan, incorporating the essential components discussed above, is available on request from the authors.

We are grateful to the officers of the health authorities who completed the questionnaire.

\section{References}

1 Department of Health and Social Security. Report of the committee of inquiry into an outbreak of food poisoning at Stanley Royd Hospital. London: HMSO, 1986.

Communicable Disease Surveillance Centre. Food poisoning and salmonella surveillance in England and Wales: 1983. Br Med J 1985;291:394-6.

3 Sheard JB. Food poisoning in England and Wales during 1983. A new title but still the same problems. Environmental Health 1986;94:57-62.

Abbott JD, Hepner ED, Clifford C. Salmonella infections in hospital. A report from the PHLS salmonella sub-committee. I Hosp Infec 1980;1:307-14.

5 Palmer SR, Rowe B. Investigation of outbreaks of salmonella in hospitals. $\mathrm{Br}$ Med $\mathcal{F}$ 1983;287: 891-3.

(Accepred 6 fune 1986)

\title{
Medicolegal
}

\section{A "sad and disturbing" case of dismissal of a consultant: DHSS overruled}

\author{
CLARE DYER
}

A consultant microbiologist removed from his job after a long running dispute over the management of his laboratory broke new ground in the high court last week when he successfully challenged a Department of Health and Social Security decision confirming his dismissal. The case is the first in which judicial review, an increasingly important remedy for challenging official actions, has been used to question the fairness and validity of a decision to dispense with a consultant's services.

Dr Royce Darnell, 56, was dismissed from his post as head of the microbiology laboratory at the Royal Derbyshire Infirmary after a disciplinary inquiry under $\mathrm{HM}(61) 112$. After an appeal to a professional committee set up by the DHSS which agreed with the inquiry panel's findings of fault but decided that dismissal was not justified, the Secretary of State for Social Services, Norman Fowler, directed Trent Regional Health Authority to offer Dr Darnell an alternative post without managerial responsibility. When the authority objected that no such post was available the minister confirmed the dismissal. Last week Lord Justice Stephen Brown and Mr Justice McCowan granted Dr Darnell's application for judicial review, declared the Secretary of State's decision invalid and of no effect, and invited him to reconsider it.

\section{London NW1}

CLARE DYER, BA, BLS, solicitor and legal journalist

\section{Root of dispute in controversy over who runs laboratories}

According to the report of the professional committee, the dispute which led to Dr Darnell's suspension in June 1982 had its roots in a nationwide controversy over the management of laboratories and the role of principal medical laboratory scientific officers. When the former Public Health Laboratory Service laboratory was transferred to the area health authority in 1977 Dr Darnell was appointed an NHS consultant microbiologist. As such, he was part of the Derby division of pathology.

Dr Darnell had been told that he would be the nominated budget holder for the laboratory. Later he learnt that the laboratory's budget was to be incorporated into the system of budgeting for the division of pathology, a change which was implemented despite his opposition. Dr Darnell and the principal medical laboratory scientific officer clashed over the procedure for appointing medical laboratory scientific officers. Subsequently the chairman of pathology and administrative staff became involved. In 1980 the area health authority decided to adopt as standard procedure the appointments procedure agreed by the division of pathology. Dr Darnell indicated that he would not be responsible for any appointee selected in this way.

In December 1980 the area health authority forwarded a formal complaint to Trent Regional Health Authority about Dr Darnell's "refusal to comply with the decision of the Derbyshire Area Health Authority concerning appointment procedures for medical laboratory scientific officers." After inquiries by the regional health 